\title{
The Effectiveness of Benzoyl Peroxide 5\% Gel with $0.05 \%$ Tretinoin Gel in Patients with Mild Acne Vulgaris (Identification of P. Acnes)
}

\author{
Ma'arifah Nadjar ${ }^{1,}$, Farida Ilyas ${ }^{1}$, Safruddin Amin ${ }^{1}$, Farida Tabri ${ }^{1}$, R. Satriono ${ }^{2}$, \\ Rizalinda Sjahrir ${ }^{3}$ \\ ${ }^{1}$ Dermatovenereology Department, Medical Faculty Hasanuddin University, Makassar, Indonesia \\ ${ }^{2}$ Pediatric Departement, Medical Faculty Hasanuddin University, Makassar, Indonesia \\ ${ }^{3}$ Microbiology Department, Medical Faculty Hasanuddin University, Makassar, Indonesia

\section{Email address:} \\ maarifah.nadjar@yahoo.com (M. Nadjar), faridha.ilyas@gmail.com (F. Ilyas), Safruddin_amin@yahoo.com (S.Amin), \\ farida_tabri@yahoo.com (F. Tabri),drsatriono@yahoo.co.id (R. Satriono), rizalinda_sjahril@yahoo.com (R. Sjahril) \\ ${ }^{*}$ Corresponding author
}

\section{To cite this article:}

Ma'arifah Nadjar, Farida Ilyas, Safruddin Amin, Farida Tabri, R. Satriono, Rizalinda Sjahrir. The Effectiveness of Benzoyl Peroxide 5\% Gel with $0.05 \%$ Tretinoin Gel in Patients with Mild Acne Vulgaris (Identification of P. Acnes). American Journal of Clinical and Experimental Medicine. Vol. 4, No. 3, 2016, pp. 76-80. doi: 10.11648/j.ajcem.20160403.17

Received: March 30, 2016; Accepted: May 9, 2016; Published: May 28, 2016

\begin{abstract}
Topical tretinoin is used by the dermatolovenereologist and aesthetic physicians in patients with mild acne vulgaris, so it is necessary to be investigated. The aim of the study was to assess the effectiveness of benzoyl peroxide gel compared to tretinoin gel on persons with mild acne vulgaris and identify Propionibacterium acnes in patients with mild acne vulgaris. The research method was a clinical trial, double blind randomization. Patients with mild acne vulgaris were randomized in to 2 groups, each group was examined for clinical manifestations (comedone, papules or pustules) examination with sebumeter 815 and Polymerase Chain Reaction, every night each group was treated with benzoyl peroxide 5\% gel and tretinoin $0.05 \%$ gel in the application, and followed-up in the days of the week 2, 4 and 6 . Data were processed with MannWhitney test and Chi-Square Test. The results indicated benzoyl peroxide 5\% gel and tretinoin $0.05 \%$ gel have the same effectiveness in patients with mild acne vulgaris. But, benzoyl peroxide 5\% gel decreased blackheads faster compared to papules or pustules with $0.05 \%$ tretinoin gel. of sebum. There was no difference in levels of decrease between benzoyl peroxide $5 \%$ gel and tretinoin $0.05 \%$ gel. Propionibacterium acnes were found in patients with mild acne vulgaris before the treatment of benzoyl peroxide $5 \%$ gel and tretinoin $0.05 \%$ gel, although not found in all samples.
\end{abstract}

Keywords: Mild Acne Vulgaris, Benzoyl Peroxide 5\% Gel, Tretinoin 0.05\% Gel

\section{Introduction}

Acne vulgaris is a self-limited inflammatory skin disease of pilosebaceous gland that usually affects teenagers age group. Majority of the acne cases appear with layered polymorphic lesions, consisting of comedone, papule, pustule, and nodule with varied severity level. Acne is an abnormality especially in teenagers age, even though it can affect all age groups. Acne has an unevitable psychosocial impacts that make individual lose self confidence and depression. [1, 2]
Acne is formed in hair follicle of the skin, like cells that are buried in skin surface acne is also buried in the follicle. The increase of accummulation process together with cohesiveness increase of these cells (hyperkeratotic retention) and increase in sebum production results in the formation of comedone (plugged hair follicle containing sebum, keratin, and normal flora), its content are gathered and begin to form inflammation. The bacteria is known as Propionibacterium acnes naturally appears far in the follicle. This bacteria is not pathogenic it self but contributes to the acne development. The bacteria gather and release proinflammatory mediator 
causing the formation of papules and pustules which exacerbate the disease severity. When formed, papules or pustules can develop into nodules or cysts. [3]

The average age to suffer from acne is 11 years old in females and 12 years old in males. Acne affects males more often in teenager age. A study suggests that acne affects $56 \%$ of males and $45 \%$ of females of 14-16 years old with moderate to severe degee in $11 \%$. [4]

Etiology of acne vulgaris is not well understood. Pathogenesis of acne is a multifactorial process in the phylocebaceous gland which enable the bacteria to develop and form inflammations. There are 4 steps to identify the acne: follicular epidermal hyperproliferation, excessive sebum production, inflammation, and activation of propionibacterium acnes. Each of this processes are related each other and under the hormonal and immune system effects. [1]

Management of acne vulgaris varies depending on the type and severity of acne lesions. In mild type, the most appropriate treatment is topical treatment. Topical treatment is indicated for comedonal acne and mild to moderate papulopustular acne without scar. The topical agents included tretinoin, antimicrobial and antibacterial agents. The application is 4-8 weeks before chaging the regimen. [5]

\section{Patient and Methods}

This study was a double blind clinical trial. This study was conducted in Dermatology and Venereology Polyclinic of Wahidin Sudirohusodo Hospital, Hasanuddin Teaching Hospital, Necri Laboratory of Hasanuddin Hospital, conducted during Januari 2016 to February 2016. Study population consisted of 40 female with mild acne vulgaris patients aged 15-20 years old. These acne patients are based on combined acne severity classification (2002). Patients agreed and signed the informed consent form. Patients did not have topical treatment history in 2 weeks, not using antibiotic and anti-inflammation in the last 2 weeks, not currently having other skin diseases on face such as allergic contact dermatitis, ready to participate in evaluation and treatment as per study procedures and follow the control schedule according to study plan, and ready to participate in this study until the end of the study.

Data were collected by: 1) Interview/history taking, 2) physical evaluation by observing the clinical signs of acne vulgaris in facial area, and then calculating the papule and pustule number, and determining the acne degree by using combined acne severity classification on right-hand half face and then on left-hand half face and then the face of patients were photographed in straight sitting position, from front direction, left and right direction, 3) Measuring the sebum level using sebumeter in mild acne vulgaris patients (left and right side) by paying attention to the $\mathrm{T}$ and $\mathrm{U}$ area. Patients were followed-up (week 2, 4, and 6), 4) PCR evaluation with DNA extraction and electrophoresis of PCR result, (5) Application of benzoyl peroxide 5\% gel and tretinoin $0.05 \%$ gel.

The collected data were processed using SPSS version 17.0. Analysis hypothetical test by Uji Mann-Whitney Test and Chi-Square Test. Hypothesis was accepted when the $\mathrm{p}$ value $<0.05$.

\section{Result}

Table 1. Comparison of PCR results between benzoyl peroxide $5 \%$ gel and Tretinoin 0,05\% gel before treatment.

\begin{tabular}{|c|c|c|c|c|}
\hline \multirow{2}{*}{ Group } & \multicolumn{2}{|l|}{ PCR } & \multirow{2}{*}{ Total } & \multirow{2}{*}{$p$ value } \\
\hline & Positive & Negative & & \\
\hline Pre benzoyl peroxide $5 \%$ gel & $11(55 \%)$ & $9(45 \%)$ & $20(100 \%)$ & \multirow{3}{*}{0.527} \\
\hline Pre Tretinoin $0,05 \%$ gel & $9(45 \%)$ & $11(55 \%)$ & $20(100 \%)$ & \\
\hline Total & $20(50 \%)$ & $20(50 \%)$ & $40(100 \%)$ & \\
\hline
\end{tabular}

Note: Chi-Square Test.

Table 1 shows positive PCR results in 20samples (100\%), and negative PCR results in 20 samples $(100 \%)$.

Table 2. Comparison of sebum level of acne vulgaris patients between benzoyl peroxide $5 \%$ gel grup and tretinoin $0.05 \%$ gel group at day 0 , day 14 , day 28 and day 42 .

\begin{tabular}{|c|c|c|c|c|c|}
\hline \multirow{2}{*}{ Day } & \multirow{2}{*}{$\mathbf{n}$} & \multicolumn{2}{|l|}{ Sebum Level $\left(\mathrm{ug} / \mathrm{cm}^{-2}\right)$} & \multirow{2}{*}{ Difference } & \multirow{2}{*}{$p$} \\
\hline & & benzoyl peroxide $5 \%$ gel Median (min-max) $n=20$ & Tretinoin $0.05 \%$ gel Median $(\min -\max ) \mathrm{n}=\mathbf{2 0}$ & & \\
\hline Day 0 & 40 & $77.6(4.2-198)$ & $84.5(46-194)$ & 6.9 & 0.646 \\
\hline Day 14 & 40 & $86.1(26.2-201)$ & $63.6(28.8-194)$ & 22.5 & 0.402 \\
\hline Day 28 & 40 & $64.7(35.2-213.8)$ & $61.5(24.6-180.4)$ & 3.2 & 0.291 \\
\hline Day 42 & 40 & $47.5(21-138)$ & $61.9(27.6-140)$ & 14.4 & 0.176 \\
\hline
\end{tabular}

Note: Mann-Whitney test, Normality Test= Shapiro-wilk.

Table 2 shows the comparison of sebum level of mild acne vulgaris patients between benzoyl peroxide 5\% gel and tretinoin $0.05 \%$ gel application at day 0 to day 42 , with no significant difference $(p<0.05)$. 
Table 3. Comparison of Comedone Number of Acne Vulgaris Patients with Benzoyl Peroxide 5\% Gel and Tretinoin 0.05\% Gel Treatment.

\begin{tabular}{|c|c|c|c|c|c|}
\hline \multirow{2}{*}{ Day } & \multirow{2}{*}{$\mathbf{n}$} & \multicolumn{2}{|l|}{ Comedone Number } & \multirow{2}{*}{ Difference } & \multirow{2}{*}{$p$} \\
\hline & & Benzoyl peroxide 5\% gel Median (min-max) $n=20$ & Tretinoin $0.05 \%$ gel Median $(\min -m a x) n=20$ & & \\
\hline Day 0 & 40 & $19(10-19)$ & 19(9-19) & 0 & 0.405 \\
\hline Day 14 & 40 & $18.5(10-19)$ & $19(10-19)$ & 0.5 & 0.040 \\
\hline Day 28 & 40 & $11.5(7-19)$ & $19(4-19)$ & 7.5 & 0.002 \\
\hline Day 42 & 40 & $10(5-19)$ & $19(4-19)$ & 9 & 0.001 \\
\hline
\end{tabular}

Note: Mann Whitney Test, Normality Test $=$ Shapiro-wilk.

Table 3 indicates the comparison of comedone number of mild acne vulgaris patients between the benzoyl peroxide $5 \%$ gel and tretinoin $0.05 \%$ gel treatment at day 0 , day 14, day 28 and day 42, with p $<0.05$ only at day 14 and day 28 .

Table 4. Comparison of Papule Number of Acne Vulgaris Patients with Benzoyl Peroxide 5\% Gel and Tretinoin 0.05\% Gel Treatment.

\begin{tabular}{|c|c|c|c|c|c|}
\hline \multirow{2}{*}{ Day } & \multirow{2}{*}{$\mathbf{n}$} & \multicolumn{2}{|l|}{ Papule number } & \multirow{2}{*}{ Difference } & \multirow{2}{*}{$p$} \\
\hline & & Benzoyl Peroxide 5\% gel Median (min-max) $n=20$ & Tretinoin $0.05 \%$ gel Median (min-max) $n=20$ & & \\
\hline Day 0 & 40 & $9.5(3-14)$ & $12(4-15)$ & 2.5 & 0.035 \\
\hline Day 14 & 40 & $9(2-14)$ & $11(2-14)$ & 2 & 0.122 \\
\hline Day 28 & 40 & $6(1-12)$ & $9.5(2-14)$ & 3.5 & $0.122 *$ \\
\hline Day 42 & 40 & $3(0-10)$ & $8(2-14)$ & 5 & 0.330 \\
\hline
\end{tabular}

Note: Mann Whitney test, Normality test $=$ Shapiro-wilk, ${ }^{*}$ t-test.

Table 4 shows the comparison of papule number of mild acne vulgaris patients between benzoyl peroxide $5 \%$ gel and tretinoin $0.05 \%$ gel treatment at day 0 , day 14 , day 28 , and day 42 . Only day 0 that indicates significant results ( $\mathrm{p}<0,05$ ).

Table 5. Comparison of Pustule Number in Acne Vulgaris patients with benzoyl peroxide $5 \%$ gel and tretinoin $0.05 \%$ gel treatment.

\begin{tabular}{|c|c|c|c|c|c|}
\hline \multirow{2}{*}{ Day } & \multirow{2}{*}{$\mathbf{n}$} & \multicolumn{2}{|l|}{ Pustule Number } & \multirow{2}{*}{ Difference } & \multirow{2}{*}{$p$} \\
\hline & & Benzoyl peroxide $5 \%$ gel Median $(\min -\max ) \mathrm{n}=\mathbf{2 0}$ & Tretinoin $0.05 \%$ gel Median $(\min -\max ) \mathrm{n}=\mathbf{2 0}$ & & \\
\hline Day 0 & 40 & $1(0-8)$ & $2(0-8)$ & 1 & 0.330 \\
\hline Day 14 & 40 & $1(0-6)$ & $1.5(0-7)$ & 0.5 & 0.311 \\
\hline Day 28 & 40 & $1(0-3)$ & $2(0-9)$ & 1 & 0.210 \\
\hline Day 42 & 40 & $0(0-3)$ & $1(0-6)$ & 1 & 0.072 \\
\hline
\end{tabular}

Note: Mann Whitney test, Normality Test $=$ Shapiro-wilk.

Table 5 indicates the comparison of pustule number in mild acne vulgaris between benzoyl peroxide $5 \%$ gel and tretinoin $0.05 \%$ gel treatment at day 0 , day 14 , day 28 and day 42, with no significant difference $(p<0.05)$.

Table 6. Side effect in benzoyl peroxide $5 \%$ gel and tretinoin $0.05 \%$ gel treatment before and after treatment.

\begin{tabular}{|c|c|c|c|c|}
\hline \multirow{2}{*}{ Side Effect } & \multicolumn{2}{|l|}{ Median (min-max) } & \multirow{2}{*}{$\mathbf{n}$} & \multirow{2}{*}{$p$} \\
\hline & Benzoyl peroxide $5 \%$ gel n (20) & Tretinoin $0.05 \%$ gel n(20) & & \\
\hline Erythema & $4(33.3 \%)$ & $8(66.7 \%)$ & 12 & 0.173 \\
\hline Pruritus & $9(42.9 \%)$ & $12(57.1 \%)$ & 21 & 0.348 \\
\hline Painful & $5(29.4 \%)$ & $12(70.6 \%)$ & 17 & 0.027 \\
\hline Exfoliative & $6(30.0 \%)$ & $14(70.0 \%)$ & 20 & 0.012 \\
\hline Dryness & $2(18.2 \%)$ & $9(81.8 \%)$ & 11 & 0.014 \\
\hline Burning sensation & $0(0 \%)$ & $2(100.0 \%)$ & 2 & $0.487 *$ \\
\hline None & $3(37.5 \%)$ & $5(62.5 \%)$ & 8 & $0.695^{*}$ \\
\hline
\end{tabular}

Note: Linear Test, (*) uji Fisher's exact test.

Table 6 indicates the significant side effects observed, including the painful, exfoliative, and dryness side effects, where $\mathrm{p}<0.05$. More than one side effect were observed in some patients.

\section{Discussion}

Acne vulgaris is a common inflammatory disease of parts of follicle pilosebaseus. The disease is characterized by lesions varying in severity from open and closed comedones on the face, in mild cases are comedones, papules, nodules, and cysts either on the face or body in severe disease. [6]

The findings of this study indicate that from 40 samples of patients with mild acne vulgaris that had been evaluated by PCR, there is no significant difference between groups treated with benzoyl peroxide 5\% gel and tretinoin $0.05 \%$ gel. It was found that 11 patients in benzoyl peroxide $5 \%$ gel group were PCR positive, and 9 patients in tretinoin $0.05 \%$ gel group were PCR positive. Polymerase chain reaction is an enzymatic method to amplify DNA in vitro. Propionibacterium acnes (P. acnes) is a commensal organism on skin playing role as an opportunist pathogen. $\mathrm{P}$. acnes is 
not considered to be infectious but it has a role in the development of acne, with important factors that include micro-environment of the follicle causing the bacterial colonization into follicle duct and resulting in inflammation. There is a relationship between $\mathrm{p}$. acnes reduction and acne clinical improvement. This $\mathrm{P}$. acnes reduction is related to proinflammatory mediators reduction. Host response to inflammatory stimulus seems to explain the variation of inflammation intensity. [7] P. acnes is found in both acne affected and normal hair follicles along with other skin commensals such as Staphylococcus aureus and Malassezia spp. Although present in healthy and diseased follicles, it may be a matter of the threshold number of bacterial cells that are required to cause disease. [8] In these mild acne vulgaris patients, the PCR is sequenced to make sure if the produced sample had been accurate in showing P.acnes. The discovery and benefits of this PCR technique has a wide impact on science and technological development in acne vulgaris, particularly in dermatology field.

Patients in 15-16 years old category with benzoyl peroxide $5 \%$ gel treatment were 13 patients $(48.1 \%)$ and with tretinoin $0.05 \%$ gel were 14 patients $(51.9 \%)$. Patients in $17-18$ years old category with benzoyl peroxide 5\% gel treatment were 7 patients $(53.8 \%)$, and with tretinoin $0.05 \%$ gel treatment were 6 patients $(46.2 \%)$. Benzoyl peroxide $5 \%$ gel is generally well tolerated with minimum side effects. [9] Tretinoin $0.05 \%$ gel has been approved by FDA for use in children above 10 years old. The safety and efficacy of this agent have been documented in a large scale trial with pediatric patients between 12 to 18 years old. Topical retinoid has been widely used in this age group. [10]

Comparison of sebum level of patients with mild acne vulgaris between BPO $5 \%$ gel and tretinoin $0.05 \%$ gel treatment at day 0 to day 42 indicated no significant difference. Sebum is a complex mixture of triglyceride, ester wax, squelene, and minority of cholesterol and phospholipid. Abnormality in sebum content is considered one of the some factors invelved in acne pathogenesis, with good role in comedogenesis or in inflammatory reaction development that cause acne lesions clinicaclly. Production and secretion of sebum is a vital condition in acne vulgaris, even though the hipersecretion is not enough to initiate the development of lesion. However, sebum in acne patients are different, quantitatively and qualitatively, from sebum in patients with normal skin. [11] Tretinoin works by reducing the sebaceous gland activities, which reduces sebum production. Sebum reduction reduces the propionibacterium acnes development, accummulated in fatty acid in sebum. [12]

Comparison of comedone number of patients with mild acne vulgaris between benzoyl peroxide 5\% gel and tretinoin treatment at day 14,28 , and 42 indicated a significant difference. The comparison of papule number of patients with mild acne vulgaris between benzoyl peroxide 5\% gel and tretinoin $0.05 \%$ gel treatment indicated a signicant results only at day 0 . Comparison of pustule number of patients with mild acne vulgaris between benzoyl peroxide $5 \%$ gel and tretinoin $0.05 \%$ gel at day 0 to day 42 indicated no significant difference. Benzoyl peroxide has a keratolytic and anti-inflammatory effect which contribute to its clinical effectiveness due to lyphophylic properties, penetrating into stratum corneum and degraded into benzoic acid and hydrogen peroxide. [13] Tretinoin increases the cells turn over in skin surface, which can reduce the formation of hyperkeratinized plaque and microcomedone. [12]

Benzoyl Peroxyde (BPO) is a non-antibiotic antibacterial used as an effective treatment in mild to moderate acne vulgaris. This agent can be applied 1 to 2 times a day, with preparations that include lotion, cream, gel, foam, solution, at concentration of $1 \%, 2.5 \%, 4 \%, 5 \%$, and $10 \%$. The mechanism of this agent is to kill bacterium by oxidating the given cell membrane, at its antimicrobial activities. Several studies suggest that BPO has a keratolytic effect and antiinflammatory that contribute to its clinical effectivenesss due to its lypophylic properties. BPO penetrates into stratum corneum and damaged into benzoic acid and hydrogen peroxide [13]

BPO is effective as topical antibiotic in the treatment of inflammatory and non-inflammatory acne lesion therapy. Several studies have shown that BPO is effective in reducing inflammatory and non-inflammatory lesions, BPO has a fast action onset, good efficacy and generally weel tolerated, and no bacterial resistance to BPO. BPO can be applied 1 to 2 times a day (morning and night). [3] Some studies have implicated the use of benzoyl peroxide at concentration of $5 \%$ for mild acne vulgaris treatment with $30 \%$ of lesion reduction. [14] Resistance can be prevented by avoiding the use of antibiotic monotherapy, limiting the length of antibiotic use, and the use of antibiotics along with benzoyl peroxide if possible. [15]

Topical retinoid is appropriate for maintenance treatment. Topical retinoid reacts against the comedone (macrocomedone and microcomedone) and has a direct antiinflammatory effect. [16] The action mechanism of topical retinoid is by preventing the comedone development (anticomedogenic) and healing the existing comedone (comedolytic), Retinoid acid activate the nuclear retinoid acid receptors, where it increases the tur over of follicular epithelial cells and recovering the abnormal desquamation, reduce comedogenesis and trigger the resolution of comedone development. Several studies have suggested that topical retinoid has a direct effect as anti-inflammatory agent that is related to non-specific immunity modulation, including the TLR2 receptor reduction, inflammation mediator, and change the inflammatory cell activity. [13] The most common side effect is pruritus om 21 patients (9 [42.9\%] in benzoyl peroxide 5\% gel group and 12 [57.1\%] in tretinoin $0.05 \%$ gel group. Whereas the exfoliative skin was observed in 20 patients (6 [30\%] in benzoyl peroxide 5\% gel group and 12 [70.6\%] in tretinoin $0.05 \%$ group. The side effects of bezoyl peroxide included skin irritation (dryness, stinging sensation, burning sensation, erythema, or exfoliative skin). [3] The most frequent side effect of retinoid topical was local irritation, including erythema, dryness, burning sensation, exfoliation and pruritus. [13] 


\section{Conclusions}

This study concludes that benzoyl peroxide 5\% gel and tretinoin $0.05 \%$ gel have the same effectiveness in patients with mild acne vulgaris. However, benzoyl peroxide $5 \%$ gel is faster in reducing comedone, papule or pustule compared to tretinoin $0.05 \%$ gel. Decreased sebum level indicated no significant difference between benzoyl peroxide $5 \%$ gel and tretinoin $0.05 \%$ gel. P. acnes were found in patients with mild acne vulgaris before the administration of benzoyl peroxide $5 \%$ gel and tretinoin $0.05 \%$ gel, although not in all samples.

\section{References}

[1] Zaeglein A. et al. Acne vulgaris and acneiform eruptions. In wolf, K. Goldsmith, L, Katz, S. Gilchrest, B, Paller, A. \& Leffell, D. Eds. Fitzpatrick's dermatology in general medicine. New York. $8^{\text {th }}$ ed. 2012. 1264-1290.

[2] Zaenglein, A. L. Thiboutot, D. M. Acne vulgaris. Dermatology. J. L. Bolognia, J. L. Jorizzo and J. V. Schaffer. USA, elsevier. 2011; 36: 545-559.

[3] Benner N. \& Sammons D. Overview of the treatment of acne vulgaris. Osteophatic Fam Physician J. 2013; 5: 185-190.

[4] Layton A. M. Disorders of the Sebaceous Glands. Burns T. Breathnach S, Cox N, Griffiths C, editors. Rook's Textbook of Dermatology. $8^{\text {th }}$ ed. Wiley-Blackwell. 2010. p. 42. 17-42.55.

[5] Kraft, J., Freiman, A. Management of Acne. Canadian Medical Association J. 2011; 183 (7): 430-435.

[6] Koo, E, B., Petersen, T, D, Kimball, A. B. Meta-Analysis Comparing Efficacy Of Antibiotics Versus Oral
Contraceptives In Acne Vulgaris. J Am Acad Dermatol. 2014; $1-9$.

[7] Gollnick H. \& Cunliffe W. Management of acne are report from a global alliance to improve outcome in acne. $\mathrm{J} \mathrm{Am} \mathrm{Acad}$ Dermatol. 2003; 49: S1-38.

[8] Achermann Y. et al. Propionibacterium acnes: from Commensal to Opportunistic Biofilm-Associated Implant Pathogen. Clinical Microbiology Reviews J. 2014; 27: 419440.

[9] Ramanathan S. and Hebert A. A. Management of acne vulgaris. J pediatr Health Care. 2011; 25: 332-337.

[10] Eichenfield L. F. et al. Evidence-Based Recommendations for the Diagnosis and Treatment of Pediatric Acne. Acad Pe J. 2013; 131, 163-182.

[11] Pappas, A., Johnsen, S., Liu, C. J. Eisinger, M. Sebum analysis Of Individuals with and without Acne. Dermatoendocrinology. 2009; 1:3. 157-161.

[12] Wolff K. et al. Topical tretinoin, Fitzpatrick's Dermatology in General Medicine, Ac. 2008; 3789-3797.

[13] Malhotra N, et al. Real World Acne Therapy in Primary Care. Dermatol J. 2012; 5: 29-43.

[14] Liao DC. Management of Acne. Fam J Pract. 2003; 52: 43.

[15] Ramdani R, 1 Sibero, H. T. Treatment for Acne Vulgaris. $J$ Majority. 2015; 4: 87-95.

[16] Tsatsou F. \& Christos. C. Z Acne vulgaris. Treatment of Skin Disease: Comprehensive Therapeutic Strategies. M. G. Lebwohi, W. R. Heymann, J. B.-- jones and I. Coulson. New York, Elsevier. 3. 2014. 6-11. 